\title{
Invasion of Retinal Pigment Epithelial Cells: N-cadherin, Hepatocyte Growth Factor, and Focal Adhesion Kinase
}

\author{
Elisabeth H. Van Aken, ${ }^{1}$ Olivier De Wever, ${ }^{2}$ Leen Van Hoorde, ${ }^{2}$ Erik Bruyneel, ${ }^{2}$ \\ Jean-Jacques De Laey, ${ }^{1}$ and Marc M. Mareel ${ }^{2}$
}

Purpose. To investigate the role of N-cadherin and hepatocyte growth factor (HGF) in the invasion of collagen type I by human retinal pigment epithelial (RPE) cells.

Methods. RPE sheets from eight human eyes were used for characterization through Western blot analysis of the expression of cadherin in total lysates or after immunoprecipitation with anti $\beta$-catenin antibody. First-passage primary cultures of RPE sheets were successfully established from 28 of 56 human eyes. First-passage primary RPE cell cultures on glass substrate, consisting of patches of cells, were used for immunocytochemistry. Fifteen first-passage primary RPE cell cultures in culture vessels were grown to confluence. Four of the 15 first-passage primary RPE cell cultures were investigated for cadherin expression by immunocytochemistry, and the other 11 were further subcultured for two to six passages. These 11 cultures were used for functional assays and investigated for expression of cadherin at regular time intervals. Cells from passage- 3 to -4 primary RPE cell cultures were tested for invasion into collagen type I gels, with or without neutralizing antibodies for HGF and $\mathrm{N}$-cadherin, respectively. Activation of the c-Met receptor for HGF and of focal adhesion kinase (FAK) was investigated by immunoprecipitation with anti-phosphotyrosine antibody, gel electrophoresis, and immunostaining on Western blot. Levels of HGF in conditioned medium (CM) of RPE cells were determined by ELISA.

Results. RPE cells in culture displayed two phenotypes: Both fibroblast-like and epithelioid cells were present in all 15 firstpassage primary cultures and in further passaged cultures derived therefrom. When seeded on collagen, all RPE cells acquired a fibroblast-like phenotype and invaded the collagen type I gel. RPE cells also stimulated branching morphogenesis of MDCK/AZ epithelial canine kidney cell colonies inside collagen. HGF was found in RPE CM, suggesting an autocrine loop for invasion through its c-Met receptor. HGF-neutralizing antibody inhibited invasion of collagen. The major cadherin expressed by RPE cells in culture was N(euronal)-cadherin. Invasion of collagen by RPE cells was also inhibited by an $\mathrm{N}$-cadherin-neutralizing antibody. N-cadherin and c-Met coimmunoprecipitated in RPE cells. FAK and c-Met were both phosphorylated in RPE cells in culture, and phosphorylation was inhibited by antibodies neutralizing either N-cadherin or HGF.

From the ${ }^{1}$ Department of Ophthalmology and the ${ }^{2}$ Laboratory of Experimental Oncology, Ghent University Hospital, Gent, Belgium.

Supported by the Fund for Research in Ophthalmology, Leuven, Belgium (EHvA). EHvA is a research assistant with the Fund for Scientific Research (FSR), Flanders, Brussels, Belgium.

Submitted for publication November 2, 2001; revised August 22, 2002; accepted September 20, 2002.

Commercial relationships policy: $\mathrm{N}$.

The publication costs of this article were defrayed in part by page charge payment. This article must therefore be marked "advertisement" in accordance with 18 U.S.C. $\$ 1734$ solely to indicate this fact.

Corresponding author: Marc M. Mareel, Laboratory of Experimental Cancerology, Ghent University Hospital, De Pintelaan 185, B-9000 Gent, Belgium; marc.mareel@rug.ac.be.
Conclusions. The present investigation provides evidence for an autocrine $\mathrm{HGF} / \mathrm{c}-\mathrm{Met}$ loop that stimulates RPE cell invasion into collagen through FAK. The invasion-stimulatory molecule $\mathrm{N}$-cadherin also activates FAK in invasive RPE cells. (Invest Ophthalmol Vis Sci. 2003;44:463-472) DOI:10.1167/iovs.011096

$\mathbf{R}$ etinal pigment epithelial (RPE) cells are unique, in that they maintain a polarized epithelioid phenotype in vivo and become rapidly fibroblastic and invasive when explanted in vitro. ${ }^{1}$ In the normal eye, RPE cells are nonproliferative, stationary phagocytes. ${ }^{2}$ They differ from most other epithelia by having no desmosomes ${ }^{3}$; the apical, instead of basolateral, localization of their sodium-potassium pump ${ }^{4-6}$; and their apical contact with the neuroretina, instead of a cell-free lumen. In culture, RPE cells proliferate and produce a morphotypically heterogeneous population with fibroblastic and also epithelioid cells. ${ }^{7}$ When explanted on collagen type I gels in vitro, RPE not only proliferates but also become invasive, ${ }^{1}$ and this situation has been related to proliferative vitreoretinopathy (PVR). ${ }^{2}$ During wound healing in diabetic retinopathy, eye injury, inflammatory eye disease, untreated or surgically treated retinal detachment, PVR is an undesirable complication. ${ }^{8}$ It is characterized by scarlike contractile connective tissue containing fibroblasts, fibroblastic RPE cells, glial cells, inflammatory cells such as macrophages and lymphocytes, and ECM molecules that comprise collagen type I. ${ }^{2,9}$

In the present experiments, we explored the mechanisms by which RPE cells shift from the epithelioid to the fibroblastic morphotype and acquire invasive properties. Candidate molecular players comprise cadherin cell-cell adhesion complexes, HGF/C-Met motility signaling, and integrin cell-matrix adhesion complexes. N-cadherin, a $135-\mathrm{kDa}$ member of the type I cadherin subfamily, is the major cadherin expressed in human RPE in vivo. ${ }^{10,11}$ Some epithelioid RPE cells also begin to express E-cadherin after prolonged culture. ${ }^{11}$ In nonepithelial cells, such as the neuroretina, ${ }^{12} \mathrm{~N}$-cadherin is linked to $\alpha$ - and $\beta$-catenin-forming adherens junctions. In embryonic and neoplastic epithelial cells, the expression of $\mathrm{N}$-cadherin has been associated with motility and invasion. ${ }^{13}$ The list of cytokines that modulate the functions of cadherin-catenin complexes includes HGF, a heterodimeric protein consisting of a $62-\mathrm{kDa}$ $\alpha$-chain and a $32 / 34-\mathrm{kDa} \beta$-chain. ${ }^{14}$ HGF evokes multiple cellular responses through binding to its tyrosine kinase receptor c-Met. ${ }^{15}$ In human breast and colon carcinoma cells, HGF inhibits cell-cell adhesion and stimulates invasion, presumably through tyrosine phosphorylation of $\beta$-catenin and weakening of the E-cadherin-catenin complex. ${ }^{16,17}$ Stimulation of migration in c-Met-expressing RPE cells by HGF suggests a role for c-Met signaling in the pathogenesis of PVR. ${ }^{18,19,20}$ One way by which HGF/c-Met signaling stimulates invasion is through activation of ECM proteases. ${ }^{21,22}$ Another target of this positive invasion-signaling pathway is cell-matrix interaction in which focal adhesion kinase (FAK), a 125-kDa cytoplasmic tyrosine kinase, is a key regulator. Exogenous HGF promoted integrin clustering and invasion of breast carcinoma cells. ${ }^{23}$ HGF-mediated activation of FAK, stimulated the migration of breast 
carcinoma cells ${ }^{24}$ and of FAK-transfected Madin-Darby canine kidney (MDCK) cells ${ }^{25}$ through filters coated with collagen type I.

When isolated from the eye, RPE cells become invasive into collagen. ${ }^{1}$ The present investigation provides evidence for an autocrine HGF/c-Met loop that stimulates RPE cell invasion of collagen through FAK. The invasion-stimulatory molecule $\mathrm{N}$ cadherin also activates FAK in invasive RPE cells. Moreover, there is a link between the HGF/c-Met/FAK and the N-cadherin/FAK pathways.

\section{Material ANd Methods}

\section{Tissues, Primary Cell Cultures, and Cell Lines}

RPE was removed from 64 donor eyes (obtained within 24 hours of death from the Eye Bank of the NORI, Amsterdam, The Netherlands) that were enucleated for the purpose of corneal transplantation, as described earlier, with minor modifications ${ }^{26}$ Briefly, the vitreous and neural retina were removed and the choroid together with the RPE was taken for incubation during 30 minutes at $37^{\circ} \mathrm{C}$ with $20 \mathrm{mg} / \mathrm{mL}$ Dispase (Roche Diagnostics, Mannheim, Germany). Then, the RPE was dissected and fragmented, and the purity of the RPE tissue was evaluated microscopically. RPE from eight eyes was brought into lysis buffer for the preparation of total lysates and for immunoprecipitation (Fig. 1). From the remaining 56 eyes, first-passage primary RPE cell cultures were established: RPE sheets from 22 eyes were seeded on $2.25-\mathrm{cm}^{2}$ glass coverslips and RPE sheets from 34 eyes into $75-\mathrm{cm}^{2}$ plastic culture vessels. The success rate was $13(59 \%)$ of 22 eyes on glass coverslips and 15 (44\%) of 34 eyes in plastic culture vessels. All RPE sheets were explanted in RPMI 1640 medium (Gibco, Merelbeke, Belgium), supplemented with $20 \%$ fetal calf serum (FCS, Gibco), $2 \mathrm{mM}$ L-glutamine, $100 \mathrm{IU} / \mathrm{mL}$ penicillin, $100 \mu \mathrm{g} / \mathrm{mL}$ streptomycin, and 2.5 $\mu \mathrm{g} / \mathrm{mL}$ amphotericin B. All 13 first-passage primary RPE cell cultures on glass coverslips were fixed in methanol after 2 to 3 days of culture and stored at $-20^{\circ} \mathrm{C}$. Eight of the former first-passage primary RPE cell cultures were used for immunocytochemistry. The 15 first-passage primary RPE cell cultures in $75-\mathrm{cm}^{2}$ tissue culture flasks were grown to confluence (BD Biosciences Labware, Franklin Lakes, NJ) and four of these were used for immunocytochemistry. Eleven RPE subcultures were isolated by trypsin treatment from the remaining first-passage primary RPE cell cultures and used for functional assays. RPE cell cultures were routinely examined by phase-contrast microscopy, immunocytochemistry, and Western blot to determine confluence and expression of cadherin and cytokeratin. The human neuroblastoma cell line SK-N-SH served as the positive control in molecular, immunocytochemical, and functional analyses of human N-cadherin-expressing cells. ${ }^{27}$ The canine kidney epithelial cells $\mathrm{MDCK} / \mathrm{AZ}^{28}$ and the rat myofibroblasts DHD-FIB ${ }^{29}$ were used respectively as noninvasive and invasive controls in the collagen type I assay. Canine kidney epithelial cells MDCKts. $\operatorname{srcCl}^{30}$ were used as a positive control for HGF-stimulated invasion. Conditioned medium (CM) of human colon cancer myofibroblasts CT5.3 ${ }^{31}$ producing $\mathrm{HGF}$, was used as a positive control for the induction of branching of MDCK/AZ cells expressing c-Met, inside collagen type I. ${ }^{32} \mathrm{CM}$ was harvested from two passage- 4 primary RPE cell cultures (6-8 weeks old, covering $75 \mathrm{~cm}^{2}$ ), from a passage- 5 to -6 primary CT5.3 cell culture (passages 5-6, 1 week old, covering 75 $\mathrm{cm}^{2}$ ) and an MRC-5 cell line (passage 15-16, 1 week old, covering 75 $\mathrm{cm}^{2}$ ), expressing $\mathrm{HGF}$, as follows. CM was collected over a total time of 72 hours, centrifuged for 10 minutes $\left(1250 \mathrm{~g}\right.$ at $\left.4^{\circ} \mathrm{C}\right)$, and passed through a filter with a $0.2-\mu \mathrm{m}$ pore size (Schleicher \& Schuell, Dassel, Germany). CM was stored at $-20^{\circ} \mathrm{C}$ until use for functional assays and for ELISA of HGF. To remove HGF from CM by immunoadsorption, 1 mL CM was incubated at $4^{\circ} \mathrm{C}$ for 3 hours with $2 \mu \mathrm{g}$ anti-HGF antibody, followed by protein $\mathrm{G}$ Sepharose 4 beads (Amersham Pharmacia Biotech, Rainham, UK) for 1 hour. This procedure was repeated a second and third time to remove all HGF. As a control for specificity of the anti-HGF antibody precipitation, an isotype mouse IgG1 antibody was used.

\section{A. Sheets}

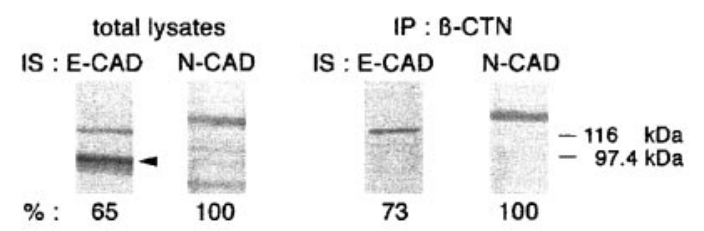

\section{B.Passage 1 primary culture, patchy}
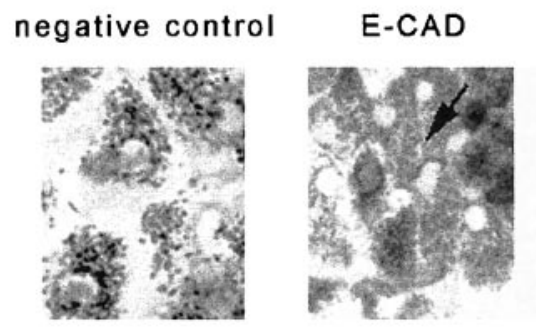

N-CAD

\section{Passage 1 primary culture, confluent}
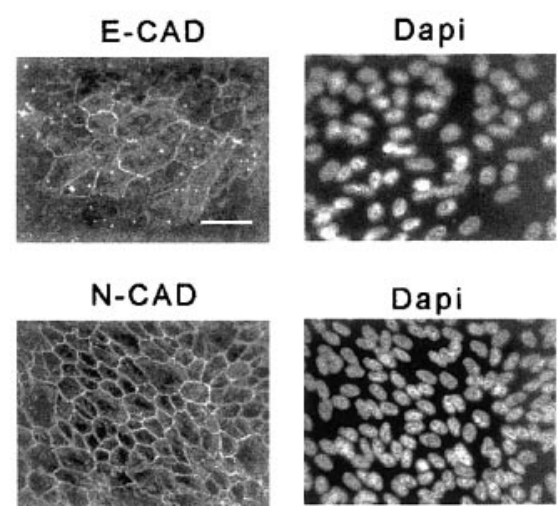

FIGURE 1. Cadherin expression in fresh RPE sheets, patchy passage-1 primary RPE cell cultures, and confluent passage- 1 primary RPE cell cultures. (A) Western blot analysis of total lysates from fresh RPE sheets and of $\beta$-catenin ( $\beta$-CTN) immunoprecipitates (IP) from the lysates, immunostained (IS) with $\mathrm{CH}-19$ and HECD-1 antibodies against $\mathrm{N}$ cadherin (N-CAD) and E-cadherin (E-CAD), respectively. Quantitation of bands at 120 and $135 \mathrm{kDa}$ was performed and data represent percentages of N-cadherin immunosignals (100\%). Arrowbead: a proteolytically generated E-cadherin fragment. The same results were obtained with fresh RPE sheets isolated from another four donor eyes. (B) Immunocytochemical staining with GC-4 and HECD-1 antibodies against $\mathrm{N}$ - and E-cadherin, respectively, followed by biotinylated antimouse immunoglobulins and streptavidin complexed with biotinylated alkaline phosphatase and fuchsin substrate chromogen. Immunocytochemical staining with a biotinylated anti-mouse immunoglobulin was used as the negative control. Arrows: cadherin-specific signals at cellcell contacts. Similar results were obtained with fresh RPE sheets isolated from six other donor eyes. (C) Immunofluorescent staining with GC-4 and HECD-1 antibodies against $\mathrm{N}$ - and E-cadherin, respectively, followed by biotinylated anti-mouse immunoglobulins and Texas-red-conjugated streptavidin. Concomitant staining of the nuclei was performed with DAPI. Similar results were obtained with fresh RPE sheets isolated from three other donor eyes. Scale bars, $20 \mu \mathrm{m}$.

\section{Antibodies and Reagents}

The following antibodies were used for the purposes indicated: rabbit polyclonal (Sigma, Bornem, Belgium), raised against a peptide corresponding to the C-terminal part (amino acids 768-781) of human 
$\beta$-catenin, for immunoprecipitation $(1 \mu \mathrm{g})$ and immunocytochemistry (diluted 1:500); mouse monoclonal, recognizing the extracellular domain of both chicken and human N-cadherin (A-CAM, clone GC-4; Sigma), for immunocytochemistry (diluted 1:30) and for functional assays (without azide and diluted 1:30); the monoclonal, neutralizing HGF, (kindly provided by Christian Gespach, National Institute of Health and Medical Research, Unit 482, Paris, France ${ }^{33}$ for functional assays; the mouse monoclonal clone SBF5 recognizing HGF (Chemicon International, Temecula, CA) for Western blot analysis and immunoadsorption of HGF from $\mathrm{CM}$; the monoclonal isotype control IgG1 clone 11711.11 (R\&D Systems, Minneapolis, MN) for the collagen type I invasion assay, the three-dimensional cultures inside collagen type I, and the immunoadsorption from CM; the mouse monoclonal, raised against the C-terminal amino acids of chicken N-cadherin (CH-19; Sigma), and the recombinant anti-phosphotyrosine RC-20 linked to horseradish peroxidase (Transduction Laboratories, San Diego, CA) for immunostaining on Western blot; a polyclonal, raised against a peptide corresponding to the C-terminal part of the $\beta$-subunit of c-Met (C-12; Santa Cruz Biotechnology, Santa Cruz, CA), for immunoprecipitation (2 $\mu \mathrm{g})$ and for immunostaining on Western blot; the monoclonal HECD-1, recognizing the extracellular domain of E-cadherin (Takara Biomedicals, Shiga, Japan), for both immunostaining on Western blot and immunocytochemistry (diluted 1:50); a monoclonal, raised against a peptide corresponding to the C-terminal part (amino acids 354-533) of FAK (Transduction Laboratories), for immunoprecipitation $(2 \mu \mathrm{g})$; the mouse anti-phosphotyrosine PY20 (ICN, Costa Mesa, CA) for immunoprecipitation $(2 \mu \mathrm{g})$; the anti-phosphotyrosine RC20 linked to horseradish peroxidase (Transduction Laboratories) for immunostaining on Western blot; a rabbit polyclonal antibody against cytokeratin (ICN) for immunocytochemistry (diluted 1:50); and recombinant HGF (rHGF; Sigma) for positive control in functional assays and immunostaining on Western blot.

\section{Immunoprecipitation, Gel Electrophoresis, and Western Blot Analysis}

Lysates were prepared from passage- 2 to -5 primary RPE cell cultures, and from RPE sheets in phosphate-buffered saline (PBS) containing 1\% Triton X-100, 1\% NP-40, and the following protease inhibitors (all from Sigma): $1.72 \mathrm{mM}$ phenylmethylsulfonyl fluoride, $21 \mu \mathrm{M}$ leupeptin, and $10 \mu \mathrm{g} / \mathrm{mL}$ aprotinin. Equal amounts of protein $(250 \mu \mathrm{g})$ were incubated with protein $G$ Sepharose beads for 1 hour, the beads were discarded, and the supernatant was incubated with primary antibody $(1-2 \mu \mathrm{g})$ for 3 hours at $4^{\circ} \mathrm{C}$ followed by incubation with protein $\mathrm{G}$ Sepharose beads for 1 hour. Precipitated proteins were washed in lysate buffer containing protease inhibitors diluted 1:10 in PBS, dissolved in sample buffer, ${ }^{34}$ boiled in the presence of $5 \%$ mercaptoethanol, separated by $7.5 \%$ SDS-PAGE and transferred onto membranes (Immobilon-P; Millipore Corp., Bedford, MA). After blockage with 5\% nonfat dry milk in PBS with $0.5 \%$ Tween-20, the membranes were incubated with anti-N-cadherin CH-19 (1:1000), anti-E-cadherin HECD-1 (1:1000), anti-FAK (1:1000), or anti-c-Met C-12 antibody (1: 200). After a wash in PBS containing 0.5\% Tween-20, the membranes were incubated with anti-rabbit or anti-mouse immunoglobulins conjugated with horseradish peroxidase. For anti-phosphotyrosine immunoprecipitation and Western blot analysis, lysates were prepared in PBS containing $1 \%$ Triton X-100, $1 \% \mathrm{NP}-40$, and the following protease or phosphatase inhibitors: $1.72 \mathrm{mM}$ phenylmethylsulfonyl fluoride, 21 $\mu \mathrm{M}$ leupeptin, $10 \mu \mathrm{g} / \mathrm{mL}$ aprotinin, $10 \mathrm{mM}$ sodium pyrophosphate, 10 $\mathrm{mM}$ sodium fluoride, and $1 \mathrm{mM}$ sodium vanadate. Precipitated proteins were washed in lysate buffer containing protease and phosphatase inhibitors diluted 1:10 in PBS. After gel electrophoresis, blot membranes were blocked in Tris buffered saline (TBS; $9 \mathrm{~g} / \mathrm{L} \mathrm{NaCl}, 1.2 \mathrm{~g} / \mathrm{L}$ Tris dissolved in aqua destillata, $\mathrm{pH} 7.6$ ) containing $0.1 \%$ Tween- 20 and $4 \%$ bovine serum albumin and were subsequently incubated with anti-phosphotyrosine RC20 linked to horseradish peroxidase (1:2500). A chemiluminescence system (ECL; Amersham Life Science, Buckinghamshire, UK) was used for protein detection on all blot membranes.
Scanning densitometry was performed with commercial software (Quantity One; Bio-Rad, Hercules, CA).

\section{Functional Assays}

For the collagen type I invasion assay and for three-dimensional cultures inside collagen, we used exclusively passage- 3 to -4 primary RPE cell cultures that had been confluent for 6 to 8 weeks, because stable RPE cell populations with different morphotypes develop in confluent cultures only after several weeks. ${ }^{35}$ The collagen type I invasion assay was performed as described. ${ }^{36}$ Briefly, collagen G (type I solution; Seromed; Biochrom KG, Berlin, Germany) was dissolved at $0.22 \%$ in bicarbonate buffer containing DMEM. Aliquots $(1.2 \mathrm{~mL})$ were poured into a six-well plate and incubated overnight at $37^{\circ} \mathrm{C}$ for gelation. RPE cells from five passage- 4 primary RPE cell cultures were seeded on top of the collagen gel without antibody in five separate wells, or were mixed with the N-cadherin-neutralizing antibody GC-4 or with HGFneutralizing antibody before seeding on top of the collagen gel. After a 24-hour incubation at $37^{\circ} \mathrm{C}$, the number of cells that invaded the gel was counted under a phase-contrast microscope with a computercontrolled step motor. The invasion index was expressed as the number of cells inside the gel over the total number of cells. The Student's $t$-test (95\%) was used for statistical analysis. For histologic evaluation of RPE cells treated with or without HGF neutralizing antibody, $300 \mu \mathrm{L}$ of a collagen solution was made as for the collagen type I invasion assay, poured into a 24-well plate and incubated overnight at $37^{\circ} \mathrm{C}$ for gelation. RPE cells $(20,000 / \mathrm{mL})$ were seeded on the collagen gel, and medium was refreshed every 2 days. After 14 days, phase-contrast micrographs were taken, and the gels were fixed with buffered formalin, embedded in paraffin, sectioned, and stained with hematoxylin and eosin. The three-dimensional cultures inside collagen type I were performed as described by Montesano et al. ${ }^{32}$ A collagen solution was made out of 7 volumes of collagen type I, 1 volume $\mathrm{NaHCO}_{3}(22$ $\mathrm{mg} / \mathrm{mL}$ ), 1 volume $10 \%$ fetal bovine serum, and 1 volume $10 \times$ DMEM. MDCK/AZ cell suspension ( $100 \mu \mathrm{L} ; 5000$ cells $/ \mathrm{mL})$ was mixed with $200 \mu \mathrm{L}$ ice-cold collagen solution and put into a 24 -well plate. The CT5.3 cells and the RPE cells from two passage- 4 primary RPE cell cultures were tested for induction of branching by putting CT5.3 CM or RPE CM on top of the gelatinized collagen-cell mixture. Cultures were incubated for 14 days at $37^{\circ} \mathrm{C}$ in a humidified atmosphere with $10 \% \mathrm{CO}_{2}$ with refreshment of the medium every 2 days.

\section{Immunocytochemistry, Immunohistochemistry, and Enzyme-Linked Immunosorbent Assay}

Eight of 13 passage-1 primary RPE cell cultures (2-3 days old, with patches of cells covering $0.04 \mathrm{~mm}^{2}$ on $2.25 \mathrm{~cm}^{2}$ glass coverslips as substrate), 4 of 15 confluent passage- 1 primary RPE cell cultures (6-8 weeks old, covering $75-\mathrm{m}^{2}$ tissue culture plastic substrate), and 11 of 11 confluent passage- 2 to -6 primary RPE cell cultures (6 - 8 weeks old, covering $2.25 \mathrm{~cm}^{2}$ glass coverslips) were fixed in methanol $\left(-20^{\circ} \mathrm{C}\right)$ for immunocytochemical staining. Aspecific binding of the primary antibody was prevented by incubation for 30 minutes with $5 \%$ bovine serum albumin. Subsequently, RPE cells were incubated with the primary antibody at room temperature for 90 minutes, followed by biotinylated immunoglobulins (diluted 1:50; Amersham) for another 90 minutes. Confluent RPE cell cultures were incubated for 15 minutes with Texas red-conjugated streptavidin (diluted 1:50) and 4',6-diamino-2-phenylindol nuclear stain (DAPI $0.4 \mathrm{mg} / \mathrm{mL}$; Sigma), mounted, and examined by fluorescence microscopy (Dialux 20; Leitz, Wetzlar, Germany). The patchy primary cultures were first incubated for 30 minutes with streptavidin complexed with biotinylated alkaline phosphatase (ABC kit; Dako A/S, Glostrup, Denmark) followed by 20 minutes' incubation with fuchsin substrate chromogen from a kit (Dako), mounted, and examined by light microscopy (Leitz). Coverslips of all cultures were mounted in aqueous medium (Glycergel; Dako). For HGF detection by ELISA, a human HGF kit was used (Quantikine; R\&D Systems) in accordance with the manufacturer's protocol. 


\section{A. Passage 2}

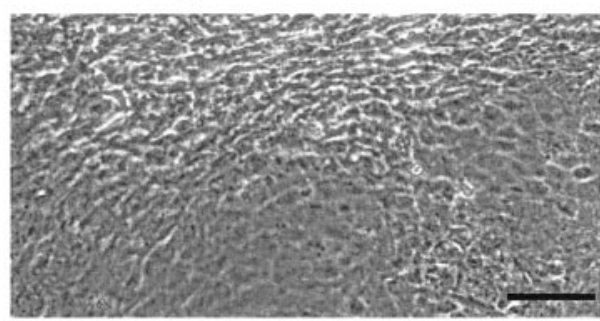

total lysates

IS : E-CAD N-CAD IS :

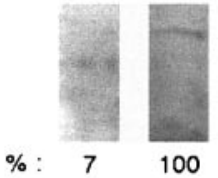

$\mathrm{N}-\mathrm{CAD}$
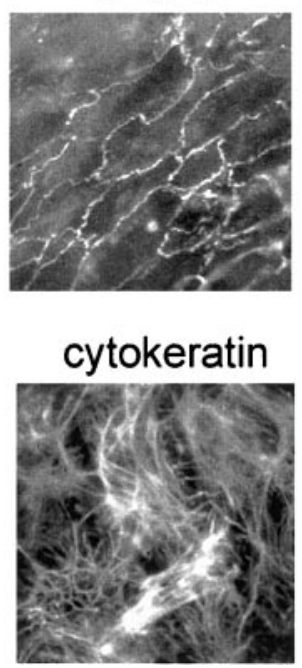

IP : B-CTN

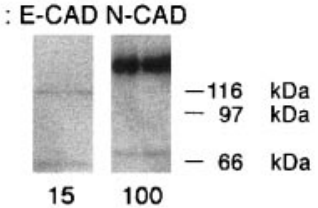

DAPI
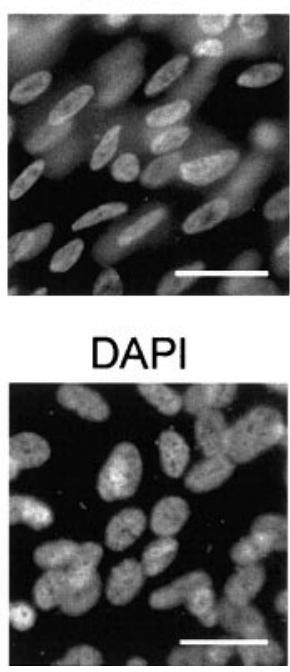

B. Passage 5

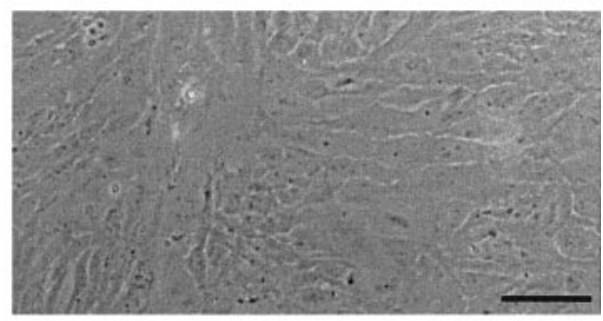

total lysates
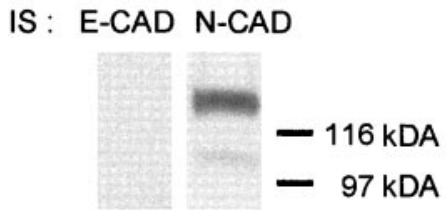

$\mathrm{N}-\mathrm{CAD}$

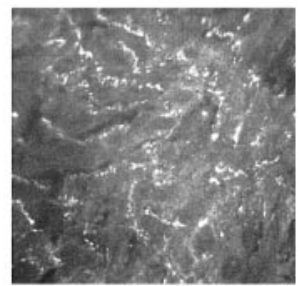

cytokeratin

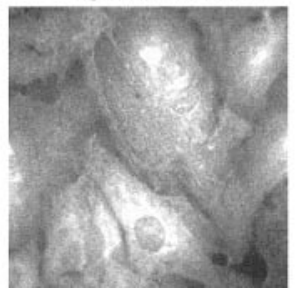

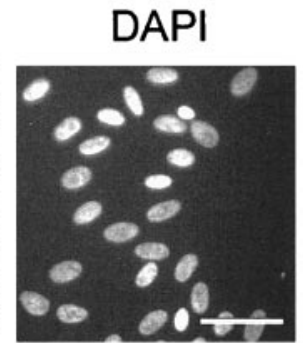

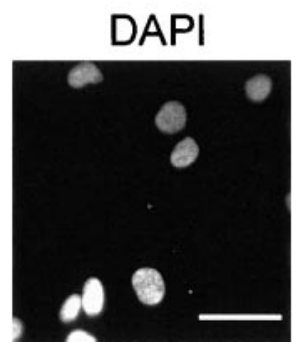

Figure 2. Heterogeneity in morphotype and cadherin expression in confluent passage-2 (A, left side) and -5 (B, right side) primary RPE cell cultures from the same donor eye. (A) Phase-contrast microphotograph of a confluent passage- 2 primary RPE cell culture. Western blot analysis of total lysates from RPE cells from a confluent passage- 2 primary culture from the same donor eye and of $\beta$-catenin ( $\beta$-CTN) immunoprecipitates (IP) from the lysates, immunostained (IS) with $\mathrm{CH}-19$ and HECD-1 antibodies against N-cadherin (N-CAD) and E-cadherin (ECAD), respectively. Data represent percentages of N-cadherin immunosignals $(100 \%)$. The same results were obtained with fresh RPE sheets isolated from three other donor eyes. Immunofluorescent staining of a confluent passage- 2 primary culture from the same donor eye with GC-4 antibody against Ncadherin or a polyclonal antibody against cytokeratin, followed by biotinylated anti-mouse immunoglobulins and Texas-red-conjugated streptavidin. Concomitant staining of the nuclei was performed with DAPI. (B) Phase-contrast microphotograph of a confluent passage-5 primary RPE cell culture. Western blot analysis of total lysates from RPE cells from a confluent passage- 5 primary culture from the same donor eye, immunostained (IS) with CH-19 antibody against N-cadherin and HECD-1 antibody against E-cadherin. The same results were obtained with fresh RPE sheets isolated from one other donor eye. Immunofluorescent staining of a confluent passage-5 primary culture from the same donor eye, performed with GC-4 antibody against N-cadherin and a polyclonal antibody against cytokeratin, followed by biotinylated anti-mouse immunoglobulins and Texas-red conjugated streptavidin. Concomitant staining of the nuclei was performed with DAPI. Scale bars: (phase-contrast micrographs), $100 \mu \mathrm{m}$; (immunofluorescence micrographs), $20 \mu \mathrm{m}$.

\section{Results}

\section{Role of N-Cadherin in RPE Cell Invasion of Collagen}

Cadherin expression was examined in fresh RPE sheets, patchy passage-1 primary RPE cell cultures and confluent passage-1 primary RPE cell cultures (Fig. 1). Total lysates from fresh RPE sheets that were not brought into culture showed an $\mathrm{N}$ - to E-cadherin ratio of 1.5:1 (range, 1.5:1-1.7:1). $\beta$-Catenin immunoprecipitates of similar lysates showed a ratio of 1.4:1 (range, 1.4:1-1.8:1; Fig. 1A). In all lysates from RPE sheets, a prominent band was visible at $90 \mathrm{kDa}$ after immunostaining with the HECD-1 antibody against E-cadherin. RPE cells in patchy passage-1 primary RPE cell cultures were E- and N-cadherin positive (Fig. 1B). Coexpression of both types of cadherin could not be evaluated, however, because heavy lipofuscin autofluorescence precluded double immunostaining. In confluent passage-1 primary RPE cell cultures, immunocytochemistry revealed $\mathrm{N}$-cadherin in all cells. E-cadherin was present only in epithelioid RPE cells (Fig. 1C). Phase-contrast microscopy and immunocytochemistry demonstrated that human RPE cultures were heterogeneous in morphotype and expression of cadherin, with variations between cultures from various donor eyes, between different passages of the same primary culture, and even within the same culture (Fig. 2). Both passage-2 and -5 primary RPE cell cultures from the same donor eye contained cells with epithelioid and fibroblastic morphotype. Total lysates from passage- 2 primary RPE cell cultures showed an Nto E-cadherin ratio of $14.3: 1$ (range, 14.3:1-15:1). $\beta$-Catenin immunoprecipitates of similar lysates showed a ratio of $6.7: 1$ (range, 6.7:1-8:1). Total lysates from passage-5 primary RPE cell cultures showed expression of N-cadherin but not of $\mathrm{E}$ cadherin. All RPE cells from passage- 2 and -5 primary RPE cell cultures, however, retained cytokeratin positivity.

When seeded on collagen type I, RPE cells from a passage- 3 primary RPE cell culture attached after 4 hours, and, after 24 hours, their morphotype was epithelioid or fibroblastic. After 7 days of culture, nearly all cells had a fibroblastic morphotype (Fig. 3). By then, single cells and cords of RPE cells were invading the gel. The role of $\mathrm{N}$-cadherin in invasion was investigated by seeding RPE cells from passage- 4 primary RPE cell cultures on a collagen type I gel, with and without N-cadherin- 

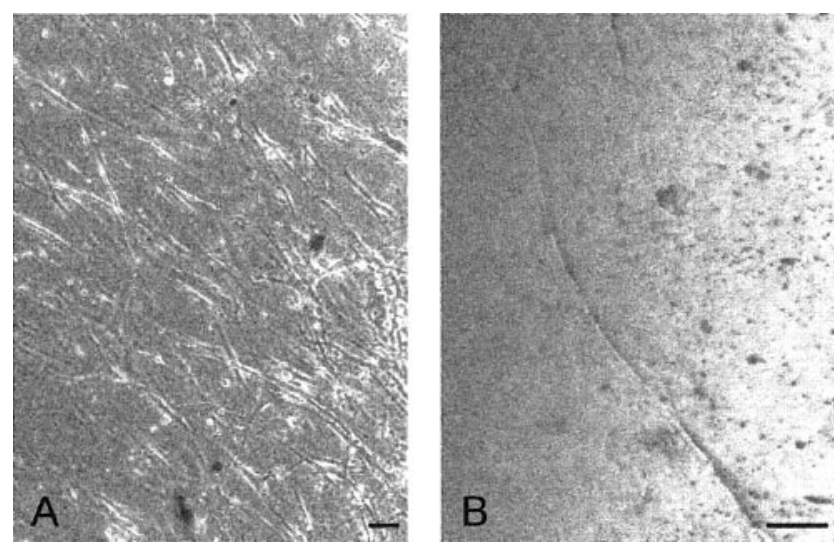

Figure 3. Human RPE cells invaded collagen type I. Phase-contrast micrographs of the surface of a collagen gel (A) and deeper into the same collagen gel (B) after 7 days of culture. RPE cells from a passage-3 primary RPE cell culture were seeded on a collagen gel at 20,000 cells/mL. The micrographs are representative of three separate experiments, with cells at the same passage isolated from three donor eyes. Scale bars, $50 \mu \mathrm{m}$.

neutralizing antibody. The invasion index of untreated RPE cells in collagen type I was approximately $8 \%$. The N-cadherinneutralizing antibody but not a control antibody of the same isotype significantly reduced the invasion indices of RPE and SK-N-SH cells (Fig. 4).

\section{Autocrine HGF/c-Met Loop in RPE Cell Invasion of Collagen}

To investigate whether RPE cells produce HGF, RPE CM was harvested from passage- 4 primary RPE cell cultures from two donor eyes, as described and tested for HGF content by ELISA (Fig. 5A). Both samples (RPE1 and RPE2) of RPE CM contained similar concentrations of HGF, although lower than the HGF concentrations found in CT5.3 CM and MRC-5 CM. CM was subsequently tested for HGF activity in three-dimensional cultures, as described by Montesano et al. ${ }^{32}$ (Fig. 5B). In this assay, both RPE CMs caused branching morphogenesis of MDCK/AZ colonies. RPE CM from which HGF had been removed by immunoadsorption with an anti-HGF antibody (Fig. 5C) did not cause branching, whereas RPE CM from which HGF could not be removed by a monoclonal isotype IgG1 antibody did. Because the passage- 4 primary RPE cell cultures produced HGF, we considered the possibility of an autocrine invasion-stimulatory loop. RPE cells from passage- 4 primary RPE cell cultures were seeded on collagen type I gels in a six-well plate for numerical evaluation of invasion and simultaneously in 24-well plates for histologic evaluation of invasion (Fig. 6). Invasion of RPE cells treated with HGF-neutralizing antibody was significantly reduced compared with untreated RPE cells. MDCKts.s$\mathrm{rcCl} 2$ cells were used as control cells, the invasion of which is stimulated by HGF. ${ }^{30}$ In this experiment also, HGF-neutralizing antibody significantly reduced invasion. Histology of paraffin sections from 14-day-old cultures confirmed that HGF-neutralizing antibody inhibited invasion. The c-Met receptor was phosphorylated in untreated RPE cells from passage- 4 primary RPE cell cultures, and addition of an HGF-neutralizing antibody reduced this phosphorylation (range, 66\%-70\%).

\section{Relation between FAK and HGF/c-Met and N-cadherin Signaling}

To investigate a possible relationship between the autocrine $\mathrm{HGF} / \mathrm{c}-\mathrm{Met}$ loop and N-cadherin on the one hand and activated FAK on the other, subconfluent passage-5 RPE cultures were starved by incubating cultures for 24 hours with serum-free medium, to avoid any interference of serum proteins with subsequent treatment or with revelation of antigens on Western blot. Subsequently, cultures were treated for another 24 hours with unsupplemented medium or with medium supplemented with HGF-neutralizing antibody or with N-cadherinneutralizing antibody. Coimmunoprecipitation of c-Met and $\mathrm{N}$-cadherin in RPE lysates immunoprecipitated with antibodies against $\mathrm{N}$-cadherin and c-Met, respectively, indicated a relationship between tyrosine kinases and cadherin complexes (Fig. 7A). Moreover, treatment of RPE cells with antibody against HGF or against $\mathrm{N}$-cadherin strongly reduced tyrosine phosphorylation of c-Met (Fig. 7B). Both neutralizing antibodies thus interfered with the autocrine HGF/c-Met loop. FAK was phosphorylated in untreated RPE cells, and this phosphorylation was reduced by $\mathrm{N}$-cadherin-neutralizing antibody (range $41 \%-57 \%$; Fig. 7C) or by HGF-neutralizing antibody (range, $5 \%-13 \%$; Fig. 7D).

\section{Discussion}

The expression of $\mathrm{N}$-cadherin and an autocrine HGF/c-Met loop were implicated in RPE cell invasion of collagen type I implicated, as evidenced by inhibition through neutralizing antibodies. RPE cells on collagen type I, besides fibronectin, a major ECM component of epiretinal membranes, started to proliferate, adopted a fibroblastic morphotype after 1 week of culture, and invaded collagen gels. RPE is, to our knowledge, the only normal adult epithelium that becomes strongly invasive in culture without the help of other cells (Ref. 1 and our present results).

Both E- and N-cadherin were found in fresh RPE sheets. In line with other observations, ${ }^{11}$ we found at the edges of RPE patches in early primary cultures cells that were N-cadherin positive but E-cadherin negative, so that in confluent primary cultures $\mathrm{N}$-cadherin became the predominant type of cadherin. ${ }^{5,10,37}$ In total cell lysates from RPE cells of confluent primary cultures, the ratio of $\mathrm{N}$ - to E-cadherin was 14.3:1 (range, 14.3:1-15:1). In total cell lysates from sheets of RPE

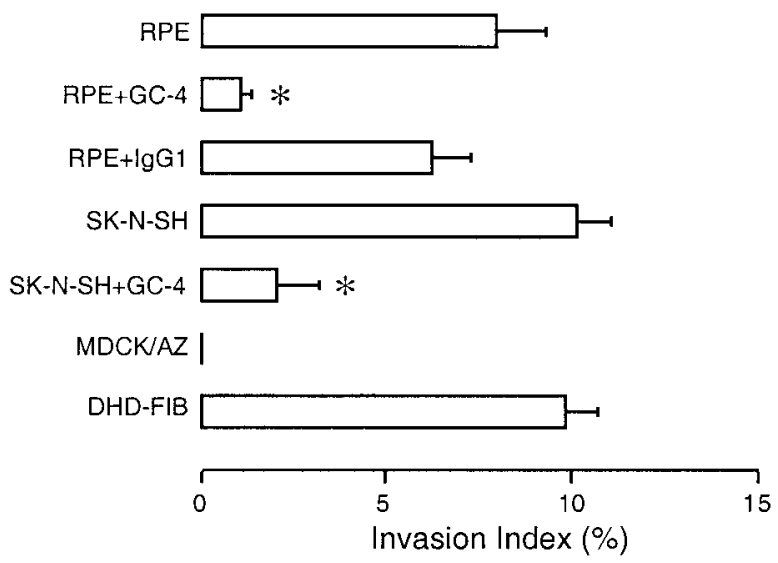

FIGURE 4. Collagen type I invasion was inhibited by GC-4 N-cadherinneutralizing antibody. Cells $\left(1 \times 10^{5}\right)$ were seeded on a collagen type I gel and left untreated or treated with GC-4 antibody or with IgG1 isotype control antibody. SK-N-SH cells served as positive control for human cells that express $\mathrm{N}$-cadherin and invade collagen type I. Invasion indices were calculated as the number of cells inside the gel over the total number of cells. Data are the mean of results in three experiments \pm SD. For each experiment, passage- 4 primary RPE cell cultures from five donor eyes were tested, and mean invasion index for RPE was calculated. *Statistically significant difference between GC-4 antibody-treated cells and untreated cells $(P<0.01)$. 
A

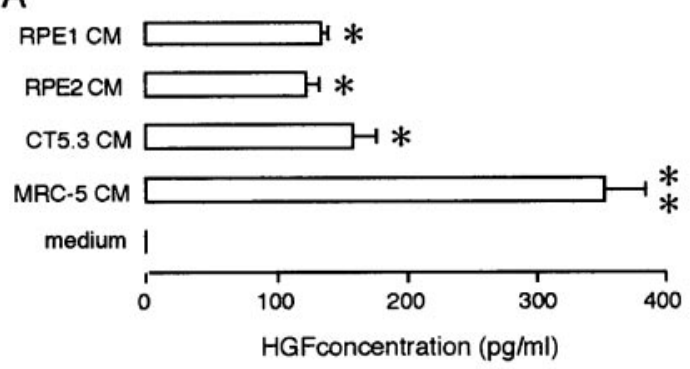

B

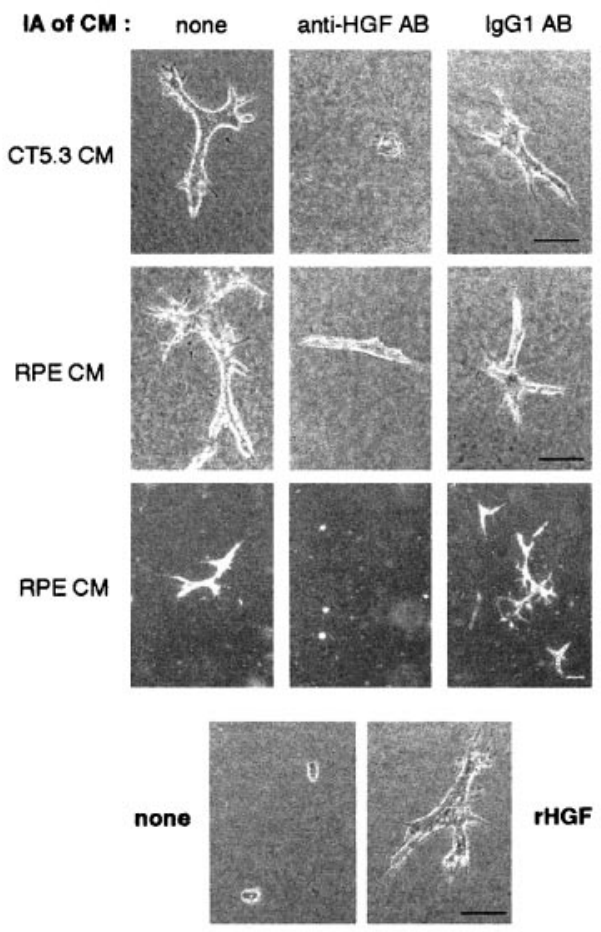

C

IA:

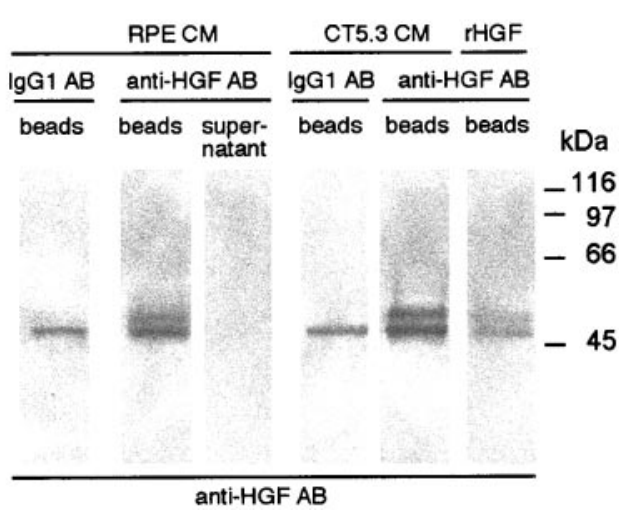

cells, the ratio of $\mathrm{N}$ - to E-cadherin was 1.5:1 (range, 1.5:1-1.7: 1). The ratio of $\mathrm{N}$ - to E-cadherin in RPE sheets was probably overestimated, because E-cadherin fragments generated by caspases during postmortem apoptosis ${ }^{38,39}$ were not taken into consideration. Preliminary immunohistochemical observations of RPE cells on collagen that have been treated with HGF-neutralizing antibody (our unpublished results) make it unlikely that the autocrine HGF/c-Met loop causes a switch from E- to N-cadherin, as occurs in chick embryo epiblast cells. ${ }^{40}$ Cytokeratin positivity argues against overgrowth of RPE cultures by contaminating cells, such as fibroblasts or endothelial cells, that normally express N-cadherin. Neither is there evidence in our data to suggest that the fresh RPE sheets consisted of the two populations of RPE cells found in 6- to 8 -week confluent cultures, one expressing only $\mathrm{N}$-cadherin and the other expressing both E- and N-cadherin. Coexpression of both cadherins in vivo has been found so far only in invasive carcinomas and transiently during embryonic development. ${ }^{41-43}$ We are, therefore, left with the scenario that RPE cells in vivo consist of two populations, one expressing Ecadherin and the other expressing N-cadherin, and that Ecadherin-expressing cells acquire $\mathrm{N}$-cadherin expression in vitro. RPE cells originate from the N-cadherin-expressing neural tube, and RPE stem cells have been described in the adult mammalian eye. ${ }^{44} \mathrm{E}$-cadherin was found in human, ${ }^{11}$ but not in rat $^{45}$ or in chick, ${ }^{46}$ RPE. At the onset of growth in culture, E-cadherin is rapidly lost and only variably reexpressed in confluent cultures after 6 to 8 weeks by cells that already are $\mathrm{N}$-cadherin positive. ${ }^{11}$

The completely different context may explain that N-cadherin serves stable cell-cell adhesion in RPE in vivo and invasion of isolated RPE cells in collagen type I. Transient Ncadherin expression is also associated with rearrangement and invasion of cells during morphogenesis ${ }^{47}$ and development of epithelial cancers ${ }^{42,48,49}$ and melanomas. ${ }^{50} \mathrm{~N}$-cadherin stimulates invasion also in retinoblastoma ${ }^{12}$ and migration of neurites in vitro. ${ }^{51}$ The apparently antithetic functions of N-cadherin can be explained by the finding that it may be mobile in the plane of the plasma membrane, thus serving migration, or may participate in the formation of stable adherens junctions that are linked to the cytoskeleton. ${ }^{52}$ This has been observed by us also in retinoblastoma compared with normal neural retina. ${ }^{12}$ Further analysis of all the elements of the N-cadherincatenin-actin complex, including their posttranslational modifications, in RPE in different contexts is needed to decide which molecules are responsible for the various phenotypes. ${ }^{53}$

The cross talk between $\mathrm{N}$-cadherin and integrin receptors may stimulate migration, such as during neurite outgrowth ${ }^{54,55}$ or cause contact inhibition of migration such as in quail myoblasts. ${ }^{56}$ In chick neural retina cells, interaction of the chondroitin sulfate proteoglycan neurocan with its GalNAcPTase receptor resulted in translocation of Fer kinase from the Ncadherin-catenin to the $\beta 1$-integrin complex. ${ }^{57}$ The hypothesis is that loss of active protein tyrosine phosphatase 1B causes hyperphosphorylation of $\beta$-catenin and uncoupling of N-cadherin from the actin cytoskeleton. In our present experiments,

adsorbed (IA) with anti-HGF antibody (anti-HGF AB) or with isotype IgG1 antibody (IgG1 AB). MDCK/AZ colonies untreated (none) or treated with recombinant $\mathrm{HGF}$ (rHGF) served, respectively, as negative and positive controls. Scale bars, $100 \mu \mathrm{m}$. (C) Western blot of RPE CM of a passage- 4 primary RPE cell culture, CT5.3 CM, and rHGF, immunoadsorbed (IA) with isotype IgG1 antibody (IgG1 AB) or anti-HGF antibody (anti-HGF AB). Beads and supernatant were separated, and proteins were resolved by SDS-PAGE, blotted, and immunostained (IS) with an anti-HGF AB. The same result was obtained with RPE CM of a passage-4 primary RPE cell culture from one other donor eye. 
A
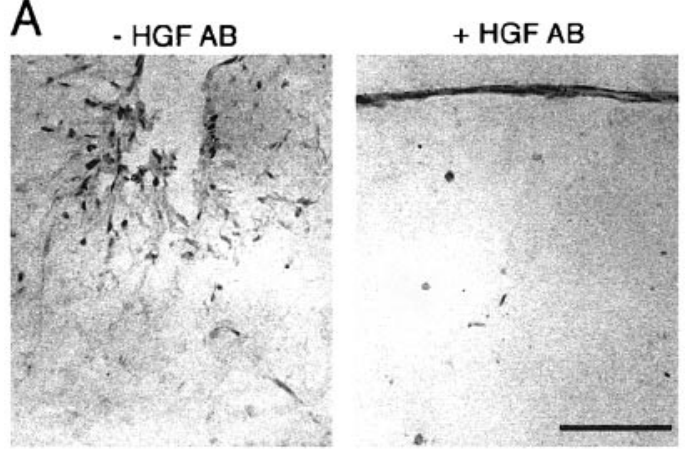

B
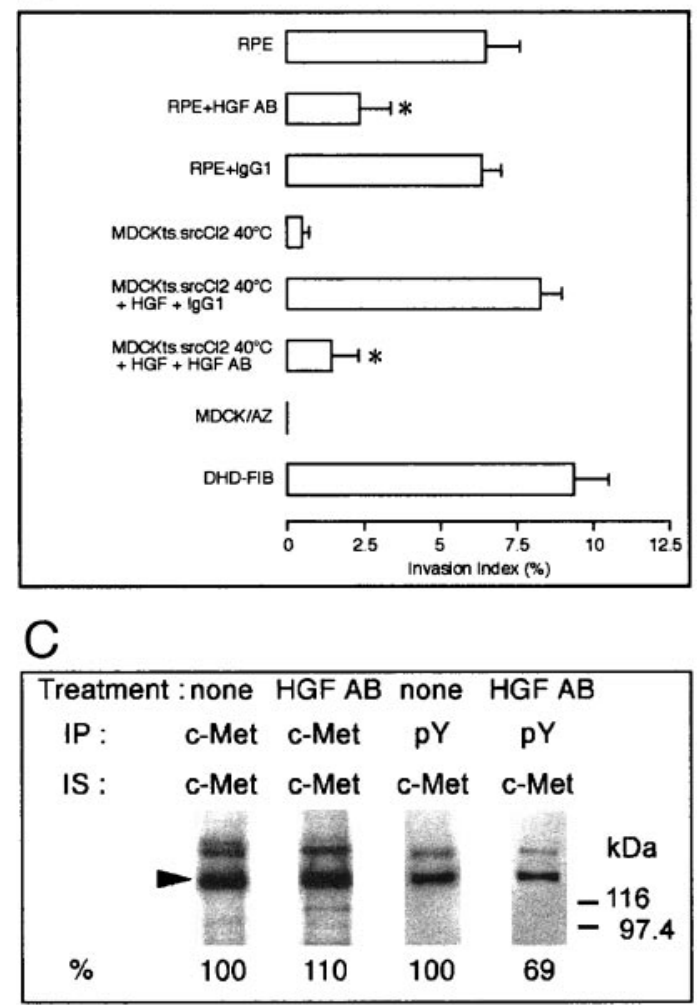

FIGURE 6. RPE cells invaded collagen type I through an autocrine HGF/c-Met loop. (A) Micrographs of paraffin sections from 14-day-old collagen cultures with RPE cells from passage- 4 primary RPE cell cultures seeded on top of the gel, either untreated (-HGF AB) or treated with HGF-neutralizing antibody (+HGF AB). The experiment was repeated twice with cells at the same passage from two donor eyes. Scale bar, $100 \mu \mathrm{m}$. (B) Numerical evaluation of RPE cell invasion in the 24-hour collagen type I invasion assay. MDCKts.srcCl2 cells were used at $40^{\circ} \mathrm{C}$ as a positive control for HGF-stimulated invasion. DHD-FIB and MDCK/AZ cells served as the control for invasive and noninvasive cells, respectively. Invasion indices were calculated as the number of cells inside the gel over the total number of cells. Data are the mean of results in three experiments \pm SD. For each experiment, passage- 4 primary RPE cell cultures from five donor eyes were tested, and the mean invasion index for RPE cells was calculated. *Statistically significant difference between HGF antibodytreated cells and untreated cells $(P<0.01)$. (C) Western blot of c-Met and PY-20 (pY) immunoprecipitates (IP) of lysates from untreated RPE cells (none) from a passage- 4 primary RPE cell culture or RPE cells treated with HGF-neutralizing $\mathrm{AB}$ (HGF AB). Precipitated proteins were separated by $7.5 \%$ SDS-PAGE, transferred onto membrane, and immunostained (IS) with antibodies recognizing c-Met (arrowhead). Data represent percentages of untreated cultures. Western blot analyses were repeated with cells at the same passage isolated from two donor eyes. both HGF-neutralizing antibody and N-cadherin-neutralizing antibody reduced phosphorylation of FAK, a signal transducer in the cell-matrix complex that regulates cell-substrate adhesion and cytoskeletal organization, two cellular activities that are crucial for invasion. ${ }^{58} \mathrm{HGF} / \mathrm{c}-$ Met not only activates FAK (Ref. 24 and our present results), but also increases integrin avidity for their ECM ligands through inside-out signaling. ${ }^{14}$ Because FAK has no SH2 domains, direct association with activated c-Met is unlikely. Possible candidate pathways between phosphorylated c-Met and FAK implicate mitogen-activated protein kinase (MAPK), PI3-K, ras, and src. ${ }^{59,60,61}$ Treatment of RPE cells with N-cadherin-neutralizing antibody also inhibited phosphorylation of the c-Met receptor, suggesting an indirect pathway over c-Met to FAK. Alternatively, Fer kinase may translocate from the N-cadherin-catenin complex to the integrin focal-adhesion complex and phosphorylate FAK. ${ }^{57}$

HGF is frequently implicated in host cell-induced cancer invasion $^{62,63}$ and in branching morphogenesis. ${ }^{64,65}$ Conflicting results appear in the literature as to whether HGF is produced by RPE cells. Lashkari et al. ${ }^{19}$ failed to detect HGF in RPE CM, nor was the c-Met receptor phosphorylated in their RPE cells in culture. By contrast, He et al. ${ }^{20}$ found HGF by RT-PCR and ELISA as well as the c-Met receptor by RT-PCR and Western blot in RPE cells in culture. In the latter and in our present experiments, the c-Met receptor was tyrosine phosphorylated. One possible explanation for discrepancies in the detection of tyrosine phosphorylation on Western blot is the difference in affinity of the phosphotyrosine antibody used. The interobserver variations in HGF contents of CM as revealed by ELISA in our study are probably not due to differences in the amount of serum, a putative source of HGF. Very little or no HGF was detected in medium that served as the negative control and that contained the same amount of serum as all other CM. It is also unlikely that activation of $\mathrm{HGF}$ by a serine protease ${ }^{66}$ secreted by RPE cells is responsible for the discrepancy, because our ELISA kit measures the sum of nonactivated and activated HGF. The HGF that was produced by two of our passage- 4 primary RPE cell cultures stimulated branching morphogenesis of epithelial MDCK/AZ cells, expressing the c-Met receptor.

Our results indicate that the HGF produced by RPE cells in culture, not only stimulated branching morphogenesis of other epithelial cells but also invasion of RPE cells. RPE cells produced HGF signals in a paracrine and autocrine way, as evidenced by our results. Treatment of RPE cells with HGFneutralizing antibody left the c-Met receptor partly (69\% of untreated) phosphorylated, and cells continued to invade to a much-reduced extent. This result is very well explained by the observation that no single antibody against HGF could inactivate its in vitro activity, because at least three epitopes should be neutralized to fully prevent tyrosine phosphorylation of its c-Met receptor. ${ }^{67}$ An autocrine invasion-stimulatory HGF/c-Met loop has been described also after transfection of c-Met-positive cells with $\mathrm{HGF}^{22,68,69}$ or with SV40 large T antigen (SV40 LT). ${ }^{70}$ Immunoreactivity for both HGF and c-Met has been reported in nonepithelial malignancies. ${ }^{33,71,72}$ Cryostat sections of normal eyes showed no immunoreactivity for HGF in RPE. $^{20}$ Vitreal aspirates of eyes with PVR, however, contain cytokines that are putative inducers of HGF and c-Met, such as PDGF, bFGF, and IL-1, possibly secreted by local inflammatory cells. ${ }^{73,74,75}$ Indeed, IL-1, bFGF, and platelet-derived growth factor (PDGF) induces HGF expression in human cutaneous fibroblasts. $^{76}$

In conclusion, we have provided evidence that, in RPE cells, $\mathrm{N}$-cadherin and an autocrine HGF/c-Met loop are two invasionpromoting complexes that may signal through the focal-adhesion complex. 
A

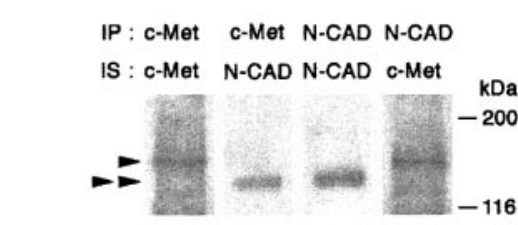

B

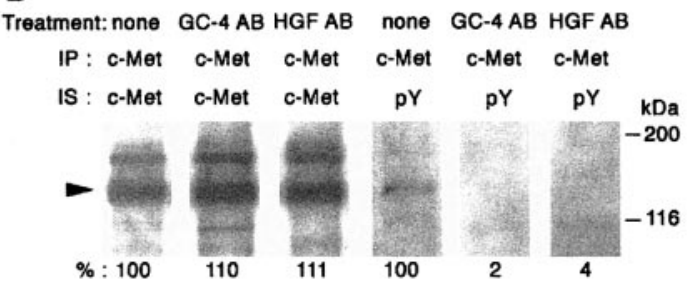

C

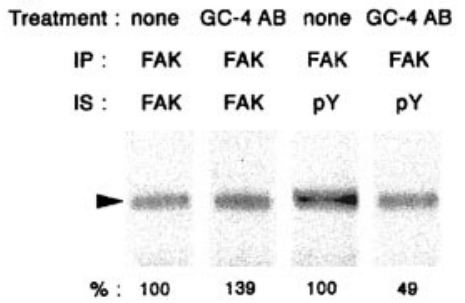

$D$

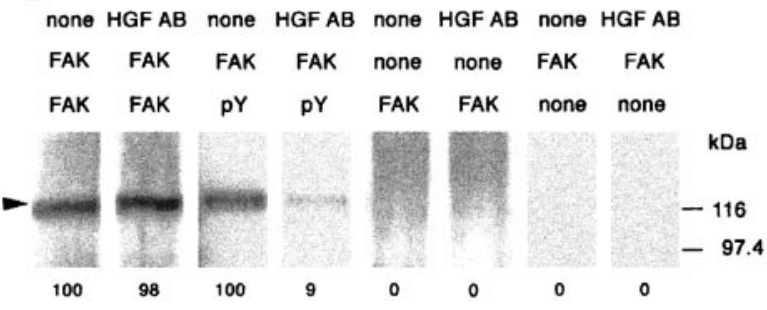

Figure 7. FAK was shown to be a downstream target of c-Met and $\mathrm{N}$ cadherin signaling in RPE cells. (A) Western blot of c-Met or N-cadherin (N-CAD) immunoprecipitates (IP) from RPE cell lysates, immunostained (IS) with antibodies recognizing cMet or N-cadherin, revealed coimmunoprecipitation of c-Met (arrowbead) and N-cadherin (double arrowheads). (B) Western blot of cMet (arrowbead) immunoprecipitates (IP) of lysates from RPE cells either untreated (none) or treated with N-cadherin-neutralizing GC-4 antibody (GC-4 AB) or with HGFneutralizing antibody (HGF $\mathrm{AB}$ ) and immunostained (IS) with an antibody against phosphotyrosine (pY) showed reduction of c-Met (arrowbead) phosphorylation. Immunostaining (IS) with the c-Met antibody (arrowbead) showed unchanged quantities of protein. (C) Western blot of FAK immunoprecipitates (IP) of lysates from RPE cells either untreated (none) or with N-cadherin-neutralizing GC-4 antibody (GC-4 AB), immunostained (IS) with antibodies against FAK or against phosphotyrosine (pY) showed reduction of FAK (arrowbead) phosphorylation. (D) Western blot of FAK immunoprecipitates (IP) of lysates from RPE cells, either untreated (none) or treated with HGF-neutralizing antibody (HGF AB) immunostained (IS) with antibodies against FAK (FAK) or against phosphotyrosine $(\mathrm{pY})$, showed reduction of FAK (arrowbead) phosphorylation. Immunoprecipitation and immunostaining without antibody against FAK (none) was performed to test antibody specificity. Data represent percentages of untreated RPE cells. Blots are representative of three experiments with passage- 5 primary RPE cell cultures from three donor eyes.

\section{Acknowledgments}

The authors thank Georges De Bruyne and Ghislaine De Smet for technical assistance and Jean Roels for preparation of the illustrations.

\section{References}

1. Docherty RJ, Forrester JV, Lackie JM. Type I collagen permits invasive behaviour by retinal pigmented epithelial cells in vitro. J Cell Sci. 1987;87:399-409.

2. Grierson I, Hiscott P, Sheridan C, Tuglu I. The pigment epithelium: friend and foe of the retina. Proc R Microsc Soc. 1997;32/33:161170 .

3. Owaribe K, Kartenbeck J, Rungger-Brandle E, Franke WW. Cytoskeletons of retinal pigment epithelial cells: interspecies differences of expression patterns indicate independence of cell function from specific complement of cytoskeletal proteins. Cell Tissue Res. 1988;254:301-315.

4. Okami T, Yamamoto A, Omori K, Takada T, Uyama M, Tashiro Y. Immunocytochemical localization of $\mathrm{Na}+, \mathrm{K}(+)$-ATPase in rat retinal pigment epithelial cells. J Histochem Cytochem. 1990;38: 1267-1275.

5. Marrs JA, Andersson-Fisone C, Jeong MC, et al. Plasticity in epithelial cell phenotype: modulation by expression of different cadherin cell adhesion molecules. J Cell Biol. 1995;129:507-519.

6. Marrs JA, Napolitano EW, Murphy-Erdosh C, Mays RW, Reichardt LF, Nelson WJ. Distinguishing roles of the membrane-cytoskeleton and cadherin mediated cell-cell adhesion in generating different $\mathrm{Na}^{+}, \mathrm{K}^{+}$-ATPase distributions in polarized epithelia. J Cell Biol. 1993;123:149-164.

7. McKay BS, Irving PE, Skumatz CMB, Burke JM. Cell-cell adhesion molecules and the development of an epithelial phenotype in cultured human retinal pigment epithelial cells. Exp Eye Res. 1997;65:661-671.

8. Pastor JC. Proliferative vitreoretinopathy: an overview. Surv Ophthalmol. 1998;43:3-18.

9. Jin M, He S, Wörpel V, Ryan SJ, Hinton DR. Promotion of adhesion and migration of RPE cells to provisional extracellular matrices by TNF-alpha. Invest Ophthalmol Vis Sci. 2000;41:4324-4332.

10. Davis AA, Bernstein PS, Bok D, Turner J, Nachtigal M, Hunt RC. A human retinal pigment epithelial cell line that retains epithelial characteristics after prolonged culture. Invest Ophthalmol Vis Sci. 1995;36:955-964.
11. Burke JM, Cao F, Irving PE, Skumatz, CMB. Expression of Ecadherin by human retinal pigment epithelium: delayed expression in vitro. Invest Ophthalmol Vis Sci. 1999;40:2963-2970.

12. Van Aken EH, Papeleu P, De Potter P, et al. Structure and function of the N-cadherin/catenin complex in retinoblastoma. Invest Ophthalmol Vis Sci. 2002;43:595-602.

13. Van Aken E, De Wever O, Correia da Rocha AS, Mareel M. Defective E-cadherin/catenin complexes in human cancer. Virchows Arch. 2001;439:725-751.

14. Trusolino L, Pugliese L, Comoglio PM. Interactions between scatter factors and their receptors: hints for therapeutic applications. FASEB J. 1998;12:1267-1280.

15. Comoglio PM. Pathway specificity for Met signalling. Nat Cell Biol. 2001;3:E161-E162.

16. Shibamoto S, Hayakawa M, Takeuchi K, et al. Tyrosine phosphorylation of $\beta$-catenin and plakoglobin enhanced by hepatocyte growth factor and epidermal growth factor in human carcinoma cells. Cell Adbes Commun. 1994;1:295-305.

17. Hiscox S, Jiang WG. Association of the HGF/SF receptor, c-met, with the cell-surface adhesion molecule, E-cadherin, and catenins in human tumor cells. Biochem Biophys Res Commun. 1999;261: 406-411.

18. Briggs MC, Grierson I, Hiscott P, Hunt JA. Active scatter factor (HGF/SF) in proliferative vitreoretinal disease. Invest Ophthalmol Vis Sci. 2000;41:3085-3094.

19. Lashkari K, Rahimi N, Kazlauskas A. Hepatocyte growth factor receptor in human RPE cells: implications in proliferative vitreoretinopathy. Invest Ophthalmol Vis Sci. 1999;40:149-156.

20. He PM, He S, Garner JA, Ryan SJ, Hinton DR. Retinal pigment epithelial cells secrete and respond to hepatocyte growth factor. Biochem Biophys Res Commun. 1998;249:253-257.

21. Pepper MS, Matsumoto K, Nakamura T, Orci L, Montesano R. Hepatocyte growth factor increases urokinase-type plasminogen activator (u-PA) and u-PA receptor expression in Madin-Darby canine kidney epithelial cells. J Biol Chem. 1992;267:2049320496.

22. Jeffers M, Rong S, Vande Woude, GF. Enhanced tumorigenicity and invasion-metastasis by hepatocyte growth factor/scatter factor-Met signalling in human cells concomitant with induction of the urokinase proteolysis network. Mol Cell Biol. 1996;16:1115-1125.

23. Trusolino L, Cavassa S, Angelini P, et al. HGF/scatter factor selectively promotes cell invasion by increasing integrin avidity. FASEB J. 2000;14:1629-1640. 
24. Beviglia L, Kramer RH. HGF induces FAK activation and integrinmediated adhesion in MTLn3 breast carcinoma cells. Int J Cancer. 1999;83:640-649.

25. Lai J-F, Kao S-C, Jiang S-T, Tang M-J, Chan P-C, Chen H-C. Involvement of focal adhesion kinase in hepatocyte growth factor-induced scatter of Madin-Darby canine kidney cells. J Biol Chem. 2000;275: $7474-7480$

26. Chang C-W, Roque RS, Defoe DM, Caldwell RB. An improved method for isolation and culture of pigment epithelial cells from rat retina. Curr Eye Res. 1991;10:1081-1086.

27. Shimono R, Matsubara S, Takamatsu H, Fukushige T, Ozawa M. The expression of cadherins in human neuroblastoma cell lines and clinical tumors. Anticancer Res. 2000;20:917-924.

28. Vleminckx K, Vakaet L Jr, Mareel M, Fiers W, Van Roy F. Genetic manipulation of E-cadherin expression by epithelial tumor cells reveals an invasion suppressor role. Cell. 1991;66:107-119.

29. Dimanche-Boitrel MT, Vakaet L Jr, Pujuguet $P$, et al. In vivo and in vitro invasiveness of a rat colon cancer cell line maintaining $\mathrm{E}-$ cadherin expression: an enhancing role of tumor-associated myofibroblasts. Int J Cancer. 1994;56:512-521.

30. Kotelevets L, Noë V, Bruyneel E, et al. Inhibition by plateletactivating factor of Src- and hepatocyte growth factor-dependent invasiveness of intestinal and kidney epithelial cells: phosphatidylinositol-3'-kinase is a critical mediator of tumor invasion. $J$ Biol Chem. 1998;273:14138-14145.

31. Van Hoorde L, Braet K, Mareel M. The N-cadherin/catenin complex in colon fibroblasts and myofibroblasts. Cell Adhes Commun. 1999;7:139-150.

32. Montesano R, Matsumoto K, Nakamura T, Orci L. Identification of a fibroblast-derived epithelial morphogen as hepatocyte growth factor. Cell. 1991;67:901-908.

33. Børset M, Lien E, Espevik T, Helseth E, Waage A, Sundan A. Concomitant expression of hepatocyte growth factor/scatter factor and the receptor c-MET in human myeloma cell lines. $J$ Biol Chem. 1996;271:24655-24661.

34. Laemmli UK. Cleavage of structural proteins during assembly of the head of bacteriophage T4. Nature. 1970;227:680-685.

35. Burke JM, Skumatz CMB, Irving PE, McKay BS. Phenotypic heterogeneity of retinal pigment epithelial cells in vitro and in situ. Exp Eye Res. 1996;62:63-73.

36. Bracke ME, Boterberg T, Bruyneel EA, Mareel MM. Collagen invasion assay. Methods Mol Med. 2001:58;81-89.

37. Liu X, Mizoguchi A, Takeichi M, Honda Y, Ide C. Developmental changes in the subcellular localization of R-cadherin in chick retinal pigment epithelium. Histochem Cell Biol. 1997;108:3543.

38. Vallorosi CJ, Day KC, Zhao X, et al. Truncation of the $\beta$-catenin binding domain of E-cadherin precedes epithelial apoptosis during prostate and mammary involution. J Biol Chem. 2000;275:33283334 .

39. Weiske J, Schöneberg T, Schröder W, Hatzfeld M, Tauber R, Huber O. The fate of desmosomal proteins in apoptotic cells. $J$ Biol Chem. 2001;276:41175-41181.

40. DeLuca SM, Gerhart J, Cochran E, et al. Hepatocyte growth factor/ scatter factor promotes a switch from E- to N-cadherin in chick embryo epiblast cells. Exp Cell Res. 1999;251:3-15.

41. Tran NL, Nagle RB, Cress AE, Heimark RL. N-cadherin expression in human prostate carcinoma cell lines: an epithelial-mesenchymal transformation mediating adhesion with stromal cells. Am J Pathol. 1999; 155:787-798.

42. Islam S, Carey TE, Wolf GT, Wheelock MJ, Johnson KR. Expression of $\mathrm{N}$-cadherin by human squamous carcinoma cells induces a scattered fibroblastic phenotype with disrupted cell-cell adhesion. J Cell Biol. 1996;135:1643-1654.

43. Takeichi M. The cadherins: cell-cell adhesion molecules controlling animal morphogenesis. Development. 1988;102:639655.

44. Tropepe V, Coles BLK, Chiasson BJ, et al. Retinal stem cells in the adult mammalian eye. Science. 2000;287:2032-2036.

45. Gundersen D, Powell SK, Rodriguez-Boulan E. Apical polarization of N-CAM in retinal pigment epithelium dependent on contact with the neural retina. J Cell Biol. 1993;121:335-343.
46. Huotari V, Sormunen R, Lehto VP, Eskelinen S. The polarity of the membrane skeleton in retinal pigment epithelial cells of developing chicken embryos and in primary culture. Differentiation. 1995;58:205-215.

47. Takeichi M. Morphogenetic roles of classic cadherins. Curr Opin Cell Biol. 1995;7:619-627.

48. Tomita K, van Bokhoven A, van Leenders GJLH, et al. Cadherin switching in human prostate cancer progression. Cancer Res. 2000;60:3650-3654.

49. Nieman MT, Prudoff RS, Johnson KR, Wheelock MJ. N-cadherin promotes motility in human breast cancer cells regardless of their E-cadherin expression. J Cell Biol. 1999;147:631-643.

50. Sandig M, Voura EB, Kalnins VI, Siu CH. Role of cadherins in the transendothelial migration of melanoma cells in culture. Cell Motil Cytoskeleton. 1997;38:351-364.

51. Utton MA, Eickholt B, Howell FV, Wallis J, Doherty, P. Soluble $\mathrm{N}$-cadherin stimulates fibroblast growth factor receptor dependent neurite outgrowth and N-cadherin and the fibroblast growth factor receptor co-cluster in cells. J Neurochem. 2001; 76:1421-1430.

52. Monier-Gavelle F, Duband, JL. Control of N-cadherin-mediated intercellular adhesion in migrating neural crest cells in vitro. $J$ Cell Sci. 1995; 108:3839-3853

53. Hamaguchi M, Matsuyoshi N, Ohnishi Y, Gotoh B, Takeichi M, Nagai Y. p60v-src causes tyrosine phosphorylation and inactivation of the N-cadherin-catenin cell adhesion system. EMBO J. 1993;12: 307-314.

54. Bixby JL, Lilien J, Reichardt LF. Identification of the major proteins that promote neuronal process outgrowth on Schwann cells in vitro. J Cell Biol. 1988;107:353-361.

55. Pathre P, Arregui C, Wampler T, Kue I, Leung TC, Lilien J, Balsamo J. PTP1B regulates neurite extension mediated by cellcell and cell-matrix adhesion molecules. J Neurosci Res. 2001; 63:143-150.

56. Huttenlocher A, Lakonishok M, Kinder M, et al. Integrin and cadherin synergy regulates contact inhibition of migration and motile activity. J Cell Biol. 1998;141:515-526.

57. Li H, Leung T-C, Hoffman S, Balsamo J, Lilien J. Coordinate regulation of cadherin and integrin function by the chondroitin sulfate proteoglycan neurocan. J Cell Biol. 2000;149:1275-1288.

58. Parsons JT, Martin KH, Slack JK, Taylor JM, Weed SA. Focal adhesion kinase: a regulator of focal adhesion dynamics and cell movement. Oncogene. 2000;19:5606-5613.

59. Chen H-C, Chan P-C, Tang M-J, Cheng C-H, Chang T-J. Tyrosine phosphorylation of focal adhesion kinase stimulated by hepatocyte growth factor leads to mitogen-activated protein kinase activation. J Biol Chem. 1998;273:25777-25782.

60. Schlaepfer DD, Hanks SK, Hunter T, van der Geer P. Integrinmediated signal transduction linked to Ras pathway by GRB2 binding to focal adhesion kinase. Nature. 1994;372:786-791.

61. Furge KA, Zhang Y-W, Vande Woude GF. Met receptor tyrosine kinase: enhanced signaling through adapter proteins. Oncogene. 2000; 19:5582-5589.

62. Bae-Jump V, Segreti EM, Vandermolen D, Kauma S. Hepatocyte growth factor (HGF) induces invasion of endometrial carcinoma cell lines in vitro. Gynecol Oncol. 1999;73:265-272.

63. Iwazawa T, Shiozaki H, Doki Y, et al. Primary human fibroblasts induce diverse tumor invasiveness: involvement of HGF as an important paracrine factor. Jpn J Cancer Res. 1996;87:1134-1142.

64. Shimura H, Date K, Matsumoto K, Nakamura T, Tanaka M. Induction of invasive growth in a gallbladder cancer cell line by hepatocyte growth factor in vitro. Jpn J Cancer Res. 1995;86:662-669.

65. Soriano JV, Pepper MS, Nakamura T, Orci L, Montesano R. Hepatocyte growth factor stimulates extensive development of branching duct-like structures by cloned mammary gland epithelial cells. J Cell Sci. 1995; 108:413-430.

66. Jiang WG, Hiscox S, Matsumoto K, Nakamura T. Hepatocyte growth factor/scatter factor, its molecular, cellular and clinical implications in cancer. Crit Rev Oncol Hematol. 1999;29:209248.

67. Cao B, Su Y, Oskarsson M, et al. Neutralizing monoclonal antibodies to hepatocyte growth factor/scatter factor (HGF/SF) display 
antitumor activity in animal models. Proc Natl Acad Sci USA. 2001;98:7443-7448.

68. Rong S, Segal S, Anver M, Resau JH, Vande Woude GF. Invasiveness and metastasis of NIH 3T3 cells induced by Met-hepatocyte growth factor/scatter factor autocrine stimulation. Proc Natl Acad Sci USA. 1994;91:4731-4735.

69. Bellusci S, Moens G, Gaudino G, et al. Creation of an hepatocyte growth factor/scatter factor autocrine loop in carcinoma cells induces invasive properties associated with increased tumorigenicity. Oncogene. 1994;9:1091-1099.

70. Martel C, Harper F, Cereghini S, Noë V, Mareel M, Crémisi C. Inactivation of retinoblastoma family proteins by SV40 T antigen results in creation of a hepatocyte growth factor/scatter factor autocrine loop associated with an epithelial-fibroblastoid conversion and invasiveness. Cell Growth Diff. 1997;8:165-178.

71. Harvey P, Warn A, Newman P, Perry LJ, Ball RY, Warn RM. Immunoreactivity for hepatocyte growth factor/scatter factor and its receptor, met, in human lung carcinomas and malignant mesotheliomas. J Pathol. 1996;180:389-394.
72. Rao UN, Sonmez-Alpan E, Michalopoulos GK. Hepatocyte growth factor and c-MET in benign and malignant peripheral nerve sheath tumors. Hum Pathol. 1997;28:1066-1070.

73. El-Ghrably IA, Dua HS, Orr GM, Fischer D, Tighe PJ. Intravitreal invading cells contribute to vitreal cytokine milieu in proliferative vitreoretinopathy. Br J Ophthalmol. 2001;85:461-470.

74. Cassidy L, Barry P, Shaw C, Duffy J, Kennedy S. Platelet derived growth factor and fibroblast growth factor basic levels in the vitreous of patients with vitreoretinal disorders. Br J Ophthalmol. 1998;82:181-185.

75. Andrews A, Balciunaite E, Leong FL, et al. Platelet-derived growth factor plays a key role in proliferative vitreoretinopathy. Invest Ophthalmol Vis Sci. 1999;40:2683-2689.

76. Nakamura T, Matsumoto K, Kiritoshi A, Tano Y, Nakamura T. Induction of hepatocyte growth factor in fibroblasts by tumorderived factors affects invasive growth of tumor cells: in vitro analysis of tumor-stromal interactions. Cancer Res. 1997;57:33053313. 